\title{
Hybrid polypeptide/polylactide
}

\section{copolymers with short phenylalanine}

\section{blocks}

Enric Mayans, ${ }^{1,2}$ Sara Keiko Murase, ${ }^{1}$ Maria M. Pérez-Madrigal, ${ }^{1,2}$ Carlos Cativiela, ,** $^{*}$ Carlos Alemán ${ }^{1,2, *}$ and Jordi Puiggalí

${ }^{1}$ Departament d'Enginyeria Química, EEBE, Universitat Politècnica de Catalunya, C/ Eduard Maristany 10-14, Ed. I2, 08019 Barcelona, Spain

${ }^{2}$ Barcelona Research Center for Multiscale Science and Engineering, Universitat Politècnica de Catalunya, Eduard Maristany 10-14, 08019 Barcelona, Spain

${ }^{3}$ Departmento de Química Orgánica and Instituto de Síntesis Quimica y Catalisis Homogenea (ISQCH), Universidad de Zaragoza-CSIC, 50009 Zaragoza, Spain 


\begin{abstract}
Hybrid copolymers constituted by shortl L-phenylalanine (Phe) blocks (i.e. Phe $_{n}$ with $n$ ranging from 2 to 25) and L-lactide blocks of different length have been synthesized and characterized. The diblock structure was obtained by ring opening polymerization of lactide using a Phe-oligopeptide as macroinitiator, which in turn was derived from the ring opening polymerization of Phe $N$-carboxyanhydride. The length of the poly(Llactide) (PLLA) block in the copolymer was effectively controlled through the [lactide] / [macroinitiator] ratio. After proving the effective coupling between the two blocks using a variety of techniques, the study has focussed on the crystalline morphologies and self-assembly characteristics of the prepared copolymers. Different morphologies were attained crystallizing from the melt or from dilute solution. In the first case, an annealing process was necessary to decrease the nucleation sites, spherulites with both positive and negative birefringence being achived as consequence of the different lamellar distributions (i.e. flat-on or edge-on arrangements). Instead, a high variety of structures were detected in the second case. Specifically, lozenge single crystals, flowerlike crystals, fibrillar structures, compact spheres, ringed sperulites with negative birefringence, dendritic structures, microfibers and braid-like microstructures were observed depending on the specific conditions (solvent, precipitant agent, temperature) and microstructure. Some of the detected morphologies are characteristic of selfassembled Phe-oligopeptides, suggesting that, despite their short size, Phe-blocks play a crucial role in the self-asembly properties of these hybrid copolymers. Overall, our results provide new fundamental understanding of the morphology of hybrid block copolymers and provide an effective tool to control the assembly of PLLA by introducing short Phe blocks. .
\end{abstract}




\section{Introduction}

Bioconjugates based on peptides coupled to biodegradable synthetic polymers have an increasing interest in different areas, especially in nanotechnology and biotechnology. In particular, polymer-peptide block copolymers (PPBC), in which peptide blocks are incorporated into the synthetic polymer, represent an important class of this type of hybrid materials, offering new possibilities to integrate the properties and function of biomolecules and synthetic polymers in a single hybrid material. ${ }^{1-5}$ Thus, PPBCs usually capture the advantages of each building block: economy, solubility, melt processability and versatility from the synthetic block, while the capacity to adopt secondary structures and self-organizing properties, functionality, high mechanical performance or biodegradability come from the peptide block. For example, PPBCs have been used to develop new bioactive hydrogels sensitive to external stimuli or with programmable responses, orthopaedic devices, biomolecular drugs, and biosensors. ${ }^{6-11}$

Among the numerous synthetic strategies reported to obtain PPBCs, ${ }^{5,12-15}$ the simplest one is probably the "grafting from" approach, which initiates the polymerization process using a macromonomer. After this, only a small component needs to be coupled to the selected macroinitiator, which can be either the peptide or the synthetic polymer, the second block being subsequently grown in a stepwise fashion.

In spite of the success of PPBCs, studies based on the combination of peptide and polyester blocks are relatively scarce. The most representative examples are triblock copolymers made of poly( $\varepsilon$-caprolactone), polylactide (PLA), poly(dimethyl trimethylene carbonate) or poly(trimethylene carbonate) blocks at both central or terminal positions with blocks constituted by different amino acids. ${ }^{16,17}$ Furthermore, diblock structures constituted by PLA and poly( $\gamma$-benzyl-L-glutamate) have also been evaluated. $^{18}$ 
In addition to its excellent properties (e.g. mechanical integrity, biocompatibility, degradability, non-toxicity of degradation products, and versatility in synthesis), ${ }^{19}$ the incorporation of PLA as a synthetic block in PPBCs is of particular interest because of the capacity of this biomaterial to adopt well defined structures, which may influence the final self-assembly properties of the engineered hybrid. When PLA is synthesized from a specific estereoisomer (e.g. PLLA produced from L-lactide), the derived material may reach a certain level of crystallinity $(\sim 40 \%)$, affecting the degradation behaviour and mechanical properties. Both processing and crystallization conditions regulate the crystalline phase, different structures ( $\alpha, \alpha^{\prime}, \beta$ and $\gamma$ phases) being possible depending on the chain conformation and packing mode..$^{20-24}$

On the other hand, the incorporation of peptide blocks into synthetic polymer chains can induce and guide molecular organization processes due to the inherent tendency of such segments to adopt well-defined structures (e.g. helical or sheet-like structures) and their ability to form specific intermolecular interactions. These characteristics allow access to a wide range of morphologies, including tapes, ribbons, cylinders, fibrils and tubes, that can be transferred to the synthetic polymer.

Despite the enormeous potential of L-phenylalanine (Phe) homopeptides to form supramolecular structures, Phe-blocks have been scarcely employed in PPBCs, copolymers with poly(ethylene glycol $)^{25}$ and polypeptides, such as poly(benzyl Lglutamate $)^{26}$ and poly(L-glutamic acid), ${ }^{27}$ being the most representative examples. Indeed, the directionality offered by the combination of hydrogen bonds and repeated phenyl stacking interactions has lead to the creation of a new famility of biomaterials based on the self-assembly capacity Phe-homopeptides, which self-organize into supramolecular structures with multiple morphologies (e.g. hollow tubes, fibrils, flat plates, stacked toroids, doughnuts, needles and dendrimers). ${ }^{28-39}$ These morphologies 
are regulated by both the chemical characteristics of the homopeptide (i.e. even or odd number of Phe residues, the $\mathrm{N}$ - and/or C-terminal capping groups, and the modifications at the Phe residues) and the experimental contiditions (i.e. solvent, peptide concentration and substrate). In particular, small Phe-based peptide molecules organized in birefringent dendritic microstructures ${ }^{32-34}$ were considered to be relevant because of the potential use of regular branched morphologies in biomedical and biotechnological applications.

Although diblock copolymers based on PLLA and very long polyPhe segments (PPhe- $b$-PLLA) were recently reported by some of us, ${ }^{40}$ in this study we focused on the supramolecular structure of PPBCs constituted by PLLA and short Phe blocks ( $b \mathrm{Phe}_{n}$, with $n$ ranging from 2 to 25 ), hereafter denoted $\mathrm{Phe}_{n}$ - $b$-PLLA. More specifically, the crystalline morphologies and self-assembly characteristics of these biomaterials have been examined considering the influence of the block length. For this purpose, Pheblocks have been synthesized through the ring opening polymerization of the $\alpha$-amino acid $N$-carboxyanhydride ( $\alpha$-NCAs), enabling the generation of peptides with a targeted

molecular weight. ${ }^{41-45}$ After this, the peptide was used as macroinitiator to produce PLLA blocks by ring opening polymerization (ROP) of L-lactide.

\section{RESULTS AND DISCUSSION}

\section{Synthesis of Phe-blocks $\left(b P_{n}\right)$}

With the exception of the very short peptide blocks ( $n=2,3$ and 4$)$, which were based on commercial di-, tri- and trephenylananine ( $\mathrm{Phe}_{2}, \mathrm{Phe}_{3}$ and $\mathrm{Phe}_{4}$, respectively), $b \mathrm{Phe}_{n}$ with $n=8,15$ and 25 were successfully obtained by means of the target Phe- $N$ carboxyanhydride (Phe-NCA) from triphosgene and Phe (Figure 1a). ROP of Phe-NCA was initiated by benzylamine as a primary amine, which was specifically chosen due to 
its similarity with the peptide chain. In addition, benzylamine appeared more effective than hexylamine, which is the initiator most usually employed. ${ }^{46}$

The molecular weights and degree of polymerization (DP) of the synthesized peptides, as determined by ${ }^{1} \mathrm{H}$ NMR spectroscopy using the intensities of the $-\mathrm{CH}_{2}-$ from the benzylamine terminal unit $(4.30 \mathrm{ppm})$ and the signals of the $-\mathrm{CH}$ - groups from the Phe unit (4.89 ppm), are displayed in Table 1. Experimental values were slightly lower than expected, which has been attributed to the low solubility of Phehomopeptides. In fact, the ratio between the experimental and theoretical DPs decreases from 0.79 to 0.63 with the increasing number of Phe units for samples obtained at the same temperature (i.e. $60^{\circ} \mathrm{C}$ ). The reaction conversion, which was evaluated through the $-\mathrm{CH}-$ signal from of $b \mathrm{Phe}_{n}(4.89 \mathrm{ppm})$ and the $-\mathrm{NH}-$ from Phe-NCA $(9.1 \mathrm{ppm})$, was high in all cases and ranged between 0.80 and 0.97 (Table 1).

DP values were also evaluated by MALDI-TOF mass spectrometry. However, the low solubility of molecules having larger number of Phe units, even in trifluoroacetic acid or HFIP, caused a partial ionization of the sample and rendered mass spectra with considerable noise. Molecular weights (not shown) were lower but at the same magniture order that those deduced from ${ }^{1} \mathrm{H}$ NMR spectra, specially for high molecular weight samples. Nevertheless, mass spectra depicted clear signals with mass difference of Phe residues (i.e. $147.1 \mathrm{~g} / \mathrm{mol}$ ) reflecting the conversion of Phe-NCA into peptides. In addition, series of signals associated with copolymers charged with a proton or a potassium cation and also with the ionization of the benzyl group were detected. This is ullustrated in Figure $2 \mathrm{a}$ for $b \mathrm{Phe}_{15}$, which shows that the maximum intensity signal corresponds to a molecular weigth of $1470 \mathrm{~g} / \mathrm{mol}$, whilethe maximum molecular weight peak was detected at $3528 \mathrm{~g} / \mathrm{mol}$. These results are in agreement with the theroretical and ${ }^{1} \mathrm{H}$ NMR values (i.e. 3047 and $2283 \mathrm{~g} / \mathrm{mol}$, respectively). 
The influence of temperature on the synthesis was evaluated by performing reactions at the same monomer / initiator ratio (M / I) ratio and polymerization time. Specifically, a set of polymerizations were conducted at $\mathrm{M} / \mathrm{I}=40$ for $48 \mathrm{~h}$ and using temperatures ranging between $25^{\circ} \mathrm{C}$ and $80{ }^{\circ} \mathrm{C}$. As it was expected, the DP increased with the temperature even though secondary reactions and backbiting were detected by ${ }^{1} \mathrm{H}$ NMR spectroscopy for reaction temperatures higher than $60^{\circ} \mathrm{C}$. Although short peptides could be obtained under milder temperature conditions, they required an increment in the initiator ratio, which lead to a DP clearly lower than expected. Hence, the synthesis of peptides with variable sizes was regulated by controlling the M / I ratio at a given temperature despite the living character of primary amine-initiated reactions (i.e. the amino end group remains active and grows when new monomer is added).

\section{Synthesis of hybrid copolymers from Phe macroinitiators}

Anionic ROP of L-lactide rings was performed though the active $-\mathrm{NH}_{2}$ groups of both commercial and synthesized $b \mathrm{Phe}_{n}$ under typical reaction conditions (i.e. $135{ }^{\circ} \mathrm{C}$ and nitrogen atmosphere). The scarce solubility of $b \mathrm{Phe}_{n}$ in the polymerization medium obligued to high polymerization times and a strict control of the occurrence of possible secondary reactions and degradation processes was carried out taken ${ }^{1} \mathrm{H}$ NMR and FTIR spectra at regular polymerization times.

In all cases, ${ }^{1} \mathrm{H}$ and ${ }^{13} \mathrm{C}$ NMR NMR spectra were in full agreement with the expected chemical structre of the copolymers, as it is illustrated in Figure $2 b$ for representative $\mathrm{Phe}_{25}-b$-PLLA 100 . Unfortunately, signals associated specifically with the Phe-Lac pair were not detected. The $-\mathrm{CH}-$ and $-\mathrm{CH}_{3}$ protons of the L-lactic acid unit were observed at $5.23 \mathrm{ppm}$ and $1.60 \mathrm{ppm}$, respectively, being clearly distinguisible from those belonging to the lactide monomer (i.e. $5.17 \mathrm{ppm}$ and $1.71 \mathrm{ppm}$ for the $-\mathrm{CH}-$ and $-\mathrm{CH}_{3}$, 
respectively). Therefore, both the NMR conversion percentage and the gel permeation chromatograpy (GPC) molecular weight measurements during the ROP of L-lactide were used to determine the optimal reaction time, which was selected to yield chain lengths in maximum agreement with the $\mathrm{M} / \mathrm{I}$ initiator ratio and to avoid molecular degradation. The final conversions and molecular weights of block copolymers obtained after reaction times comprised between 5 and 7 days are displayed in Table 2. The $\mathrm{CH}-$ proton at $4.35 \mathrm{ppm}$, which is connected to the terminal L-lactic acid unit, and the area of the signal at $5.23 \mathrm{ppm}$ were used to estimate the number of lactoyl units in PLLA blocks (DP PLLA in Table 2). The peaks assigned to with the $b \mathrm{Phe}_{n}$ units are also observed in both ${ }^{1} \mathrm{H}$ and ${ }^{13} \mathrm{C}$ NMR spectra of the produced copolymers (Figure 2b), the areas of $-\mathrm{CH}-$ signals of the $b \mathrm{Phe}_{n}(4.62 \mathrm{ppm})$ and PLLA $(5.23 \mathrm{ppm})$ blocks being employed to determine the peptide content percentage in Phe $_{n}-b$-PLLA (Table 2).

Molecular sizes obtained by GPC (Table 2) were in good agreement with the $b \mathrm{Phe}_{n}$ and PLLA block lengths determined by ${ }^{1} \mathrm{H}$ NMR spectroscopy, even though they were lower than expected from the M / I ratio. This feature has been attributed to the usual side reactions of ROP, which took place more pronouncedly because of the long reaction times required. In addition, the prepared block copolymers were in some cases hardly dissolved in HFIP (i.e. those with the higher peptide percentage), leading to a molecular weight subestimation by GPC analysis. On the other hand, the FTIR spectra of the synthesized hybrids show clear signals attributed to each block when their proportion is reasonably high. This is illustrated in Figure 3a, which compares the spectrum of $\mathrm{Phe}_{25}-b-\mathrm{PLLA}_{100}$ with the spectra of PLLA and $b \mathrm{Phe}_{25}$. Characteristic bands of PLLA and Phe are observed in the copolymer as well as in samples containing lower peptide content (i.e. $\mathrm{Phe}_{15}-b$-PLLA 50 and $\mathrm{Phe}_{8}-b-\mathrm{PLLA}_{55}$, not shown). 
Furthermore, the spectrum of the copolymer shows peaks at 1209 and $921 \mathrm{~cm}^{-1}$ (see arrows in Figure 3a), which are attributed to the typical $10_{3}$ helix of PLLA.

After reaction with lactide, the change of solubility of the different $b \mathrm{Phe}_{n}$ oligomers is the clearer observation that proves effective reaction between both block species. Peptide blocks based in Phe are practically insoluble in a high number of solvents, this effect increasing with the number of residues. Hybrid copolymers prepared in thi work are completely soluble in $\mathrm{CHCl}_{3}$ or, those with high peptide percentages, in $\mathrm{CHCl}_{3}$ with a small ratio of TFA.

$\mathrm{UV}$-Vis spectroscopy was used to confirm that $b \mathrm{Phe}_{n}$ initiators were effective for the ROP of lactide. Figure $3 b$ shows the spectra of a representative synthesized peptide $\left(b \mathrm{Phe}_{8}\right)$, three copolymers $\left(\mathrm{Phe}_{8}-b-\mathrm{PLLA}_{55}, \mathrm{Phe}_{15}-b-\mathrm{PLLA}_{50}\right.$ and $\left.\mathrm{Phe}_{25}-b-\mathrm{PLLA}_{100}\right)$, and crystalline commercial PLLA. As it can be seen, the five peaks associated with the aromatic rings of Phe (i.e. at 246, 250, 256, 262 and $266 \mathrm{~nm}$ ) are also detected in the spectra of the copolymers, while no peak is observed in the $240-270 \mathrm{~nm}$ interval of PLLA spectrum. The intensity of the aromatic peaks has some correlation with the Phe content, despite solubility problems still exist in some samples. Thus, peaks are more intense in the spectrum of $\mathrm{Phe}_{15}-b$-PLLA $_{50}$ (Phe content: $37 \%$ ) than in the spectrum of Phe $_{8}-b-$ PLLA $_{55}$ (Phe content: $\left.22 \%\right)$.

\section{Thermal properties of Phe ${ }_{n}-b$-PLLA hybrids}

The thermal stability of the copolymers was evaluated by thermogravimetric analysis (TGA). In general, two degradation steps were detected. The fist one, which appeared at temperatures lower than $300{ }^{\circ} \mathrm{C}$, involved the greater mass loss $(>70 \%)$ and was attributed to PLLA blocks. The significance of the second step, which was associated with the $b \mathrm{Phe}_{n}$ segments, decreased with the content of peptide. Figure 4a compares the 
TGA and derivative thermogravimetric analysis (DTGA) traces of $\mathrm{Phe}_{8}-b$-PLLA 55 , commercial PLLA and $b$ Phe $_{8}$. The peptide started to degrade earlier (i.e. the deviation from the flat baseline occurred at $140{ }^{\circ} \mathrm{C}$, while that of the hybrid copolymer was at 164 $\left.{ }^{\circ} \mathrm{C}\right)$. Although apparently these differences were relatively unimportant, the onset degradation temperatures are relevant since they are close to the reaction temperature selected for the ROP of lactide. Therefore, this temperature must be strictly controlled in order to avoid the decomposition of the peptide used as initiator and the unbalancing of the M / I ratio. Fortunately, the formed copolymers were stable at such reaction temperature and specially when longer L-lactide blocks were involved.

DTGA curves (Figure 4a) allow elucidation of the different degradation steps. $b \mathrm{Phe}_{8}$ exhibits a single DTGA peak temperature at $377^{\circ} \mathrm{C}$, this value being clearly higher than the peak temperature associated with to the peptide block in the $\mathrm{Phe}_{8}$ - $b$-PLLA F $_{55}$ (i.e. 340 $\left.{ }^{\circ} \mathrm{C}\right)$. This feature has been attributed to the fact that the decomposition of the peptide blocks may be enhanced by the products resulting from the previous degradation of the PLLA blocks. The thermal stability of the latter blocks, with DTGA peaks at $276{ }^{\circ} \mathrm{C}$ and $377^{\circ} \mathrm{C}$, is lower than that of commercial PLLA, even though it is in agreement with that previously reported for low molecular weight PLLA samples. ${ }^{23}$ More specifically, the high ratio of terminal groups favoured the degradation of molecules having 50 lactoyl units, which occurred at $270{ }^{\circ} \mathrm{C} .{ }^{23}$ These results deserve consideration for applications in which $\mathrm{Phe}_{n}-b$-PLLA ${ }_{m}$ copolymers require further treatment involving high temperatures.

Characterization of $\mathrm{Phe}_{n}-b$-PLLA $m$ copolymers by differential scanning calorimetry (DSC) was conducted using a well-established protocol that involves different heating and cooling scans, results being illustrated in Figure $4 \mathrm{~b}$ for $\mathrm{Phe}_{8}-b$-PLLA 5 . A single melting peak associated the fusion of the PLLA crystalline phase was observed in the different heating scans performed for all synthesized copolymers. However, a small 
shoulder, indicative of a typical lamellar reorganization of PLLA, could be envisaged in some cases. On the other hand, melting peaks associated to the peptide crystalline phase are not detected despite X-ray diffraction analyses indicate the existence of a crystalline order (see below). This has been attributed to the thermal degradation, which took place before the melting temperature of the $b \mathrm{Phe}_{n}$ blocks was reached.

All copolymers were semicrystalline when obtained from synthesis, but crystallized with difficulty from the melt state, as it is well known for PLLA. Accordingly, a clear cold crystallization peak can be observed in a subsequent heating run. Quenching from the melt rendered practically amorphous samples, as it is evidenced by the heating trace where similar enthalpies were determined for cold crystallization and melting peaks. Although the thermal behavior showed similar general trends for all the synthesized samples, some differences are among them (Table 3). More specifically, the glass transition temperature decreased with the the molecular weight, even though the variation was small and the observed values are comprised between $50{ }^{\circ} \mathrm{C}$ and $55^{\circ} \mathrm{C}$ in all cases. Obviously, these temperatures are clearly lower than that obtained for commercial PLLA samples. In addition, the increase on the Phe content lead to a lower crystallinity, a greater difficulty to crystallize from the melt and less well formed PLLA crystalline domains. This is evidenced by the lower values of the melt (i.e. $35 \mathrm{~J} / \mathrm{g}$ with respect to $6.7 \mathrm{~J} / \mathrm{g}$ ) and cold crystallization (i.e. $23.0 \mathrm{~J} / \mathrm{g}$ with respect to $19.2 \mathrm{~J} / \mathrm{g}$ ) enthalpies, the increase on the temperature of the cold crystallization peak (i.e. from 97 ${ }^{\circ} \mathrm{C}$ to $106^{\circ} \mathrm{C}$ ), and the decrease of the melting temperature (i.e. from $141^{\circ} \mathrm{C}$ to $128{ }^{\circ} \mathrm{C}$ ).

\section{Structure of Phe ${ }_{n}-b$-PLLA hybrids}

Previous studies on $\mathrm{Phe}_{n}$-PLLA conjugates, in which very short $\mathrm{Phe}_{n}$ peptides were covalently integrated at one extreme of PLLA chains, suggested that the structure of the 
polymer is guided by the peptide component. ${ }^{47}$ However, this feature is not extrapolable to $\mathrm{Phe}_{n}-b$-PLLA copolymers, which present a molecular architecture completely different from that of simple conjugates, as it is demonstrated in this section.

Powder X-ray diffractograms of synthesized copolymers showed the characteristic peaks associated with the PLLA crystalline phase and some peaks the peptide phase when its content was sufficently high. This high crystallinity is illustrated in Figure 5a for $\mathrm{Phe}_{15}-b$-PLLA 50 . Specifically, typical Bragg reflections attributed to the $\alpha$-form of PLLA $^{20}\left(10_{3}\right.$ helix) were observed in the spectra of all copolymers. The most intense reflections were detected at $0.547,0.470$, and $0.403 \mathrm{~nm}$, which were indexed as the $(200)+(110),(203)$ and $(015)$ reflections of the characteristic orthorhombic lattice $(a=$ $1.078-1.075, b=0.645-0.604$ and $c$ (chain axis) $=2.78-2.88 \mathrm{~nm}$ ). Hence, $b$ Phe blocks do not disturb the crystallization of PLLA segments, even when the weight percentage of peptide blocks is as high as $37 \%$ (Figure 5a). A reflection at $1.186 \mathrm{~nm}$ was also observed, even for short $b \mathrm{Phe}_{n}$ blocks (e.g. $n=3$ ), with variable relative intensity compared to the characteristic PLLA peak at $0.547 \mathrm{~nm}$. Obviously, the intensity of such reflection increased with the Phe-content. The calculated spacing, which is larger than the value expected for the typical $2_{1}$ conformation of $\beta$-strands (i.e. $\left.0.70 \mathrm{~nm}\right),{ }^{48}$ has been attributed to the intersheet spacing where the bulky aromatic groups should be placed.

\section{Morphology of melt crystallized hybrids}

Isothermal crystallization of the synthesized hybrids rendered very small spherulites even at low supercooling degrees. In fact, a large number of nucleation sites appeared due to the low molecular weight of the samples and especially to the presence of phase heterogeneities, which has been attributed to the self-assembly of the peptide blocks. In order to diminish the nucleation density and avoid a fast crystallization, the melted 
sample was quickly cooled to a chosen annealing temperature at which phase separation took place. ${ }^{49,50}$ Therefeore, the number of active nuclei, which were assigned to the peptide assembly, in the PLLA phase was intended to be decreased in the subsequent isothermal crystallization performed after heating again the sample above its melting temperature. The annealing temperature was chosen within the interval comprised between the temperature of beginning of the crystallization process (i.e. the end of the crystallization peak in the cooling DSC trace) and the temperature of the beginning of fusion. Withn this narrow interval, a temperature of $120{ }^{\circ} \mathrm{C}-125^{\circ} \mathrm{C}$ was appropriated for the different samples, as it is illustrated in Figures 5a-f for $\mathrm{Phe}_{8}-b$-PLLA 5 .

The size of the peculiar spherulites obtained from the melt crystallized hybrid are significantly influenced by crystallization due to the increasing nucleation with the supercooling degree. Thus, diameters close to $400-600 \mu \mathrm{m}$ were reached at temperatures close to the annealing temperature $\left(e . g .120^{\circ} \mathrm{C}\right.$ for morphologies showed in Figures $5 \mathrm{~d}$ e), whereas the size decreased down to $150 \mu \mathrm{m}$ (Figures $5 \mathrm{f}$ ) when the temperature was close to the beginning of the crystallization peak identified in the DSC trace (i.e. 115 $\left.{ }^{\circ} \mathrm{C}\right)$. Sizes of $200-250 \mu \mathrm{m}$ were observed at intermediate temperatures (e.g. $118{ }^{\circ} \mathrm{C}$ for Figures 5a-c).

In opposition to the usual negative sign of fibrilar spherulites of PLLA (i.e. the edgeon deposition of the constitutive lamellae cause a tangential orientation of polymer chains), Phe ${ }_{n}-b$-PLLA spherulites exhibited positive birefringence in all cases. This distinctive birefringence suggests a different arrangement of lamellar crystals (i.e. flaton $v s$. edge-on) inside each spherulite. In fact, umbrella-like spherulites constituted by flat-on lamellae were detected in all cases. Crystallizations conducted at $118{ }^{\circ} \mathrm{C}$ rendered spherulites in which the radial lamellae become branched, giving crystals at certain tilting angles (i.e. close to $60^{\circ}$; marked with ellipsoids in Figure 5b). Therefore, 
the birefringence of such small branches is the opposite to that of radial crystals, as it is evidenced in the polarized micrographs taken with a first order tint plate (ellipsoid in Figure 5c). This branching is more evident in the smaller spherulites obtained at lower temperature, giving rise to a highly confusing birefringence (Figure 5f). Spherulites formed at the highest temperature are larger and exhibit umbrella-like morphologies with diamond-shaped vanes associated to flat-on lamellar crystals (Figures 5d-e).

Hybrid block copolymers having short Phe-blocks displayed a differentiated morphology (Figures 5g-1). More specifically, Phe $2-b$-PLLA 45 showed banded spherulites with the negative birefringence characteristic of PLLA, suggesting that this hybrid behaves as a simple low molecular weight PLLA. The observed bright bands correspond to lamellae with an edge-on disposition, whereas the dark bands are associated with flat-on lamellae. The size of the spherulites increased with crystallization temperature, diameters close to $300 \mu \mathrm{m}$ and $2000 \mu \mathrm{m}$ being observed for crystallizations at $115^{\circ} \mathrm{C}$ (Figure $5 \mathrm{~g}$ ) and $125^{\circ} \mathrm{C}$ (Figure 5h), respectively. However, the separation between bands decreased from $85 \mu \mathrm{m}\left(115^{\circ} \mathrm{C}\right)$ to $70 \mu \mathrm{m}\left(125^{\circ} \mathrm{C}\right)$. The increase of $n$ in $b \mathrm{Phe}_{n}$ affected the morphology of the spherulites, as it is reflected by micrographs recorded for $\mathrm{Phe}_{3}-b-\mathrm{PLLA}_{44}$ (Figure 5i), Phe $4-b$-PLLA 60 (Figure 5j) and Phe $_{5}-b$-PLLA 50 (Figure 5k) crystallized at $115^{\circ} \mathrm{C}$. The birefringence was negative in all cases, even though a banded structure was hardly detected. Moreover, the morphology became progressively more irregular and the diameter decreased with the increasing size of Phe-block. Thus, values of 300, 220, 115 and $40 \mu \mathrm{m}$ were measured for $\mathrm{Phe}_{n}-n$ PLLA copolymers with $n=2,3,3$ and 5, respectively. Interesting morphologies were observed when $\mathrm{Phe}_{5}-b$-PLLA ${ }_{50}$ was crystallized at a temperature as high as $135^{\circ} \mathrm{C}$. In this case, hexagonal aggregates with a diamterer close to $150 \mu \mathrm{m}$ were formed (Figure 51). These were constituted by lath-shaped flat-on lamellae that even gave rise to 
rhombic frames. It should be remarked that the hexagonal aggregates exhibit a positive birefringence, as described above for spherulites with a planar disposition of lamellae (Figures 5d-e).

\section{Morphologies from dilute solutions}

Crystallization/precipitation from dilute solutions allows developing single entities and minimize the problems attributed to the characteristic high nucleation of melt crystallization. A wide variety of morphologies can be achieved as a function of the block that initiates the crystallization, which depends on the selected conditions (i.e. solvent and precipitating agent). Due to solubility problems, the study was limited to copolymers with $b \mathrm{Phe}_{\mathrm{n}}$ blocks with $n$ ranging from 2 to 5 and low molecular weight.

Slow evaporation at room temperature of dichloromethane solutions of $\mathrm{Phe}_{2}-b$ PLLA $_{22}(10 \mathrm{mg} / \mathrm{mL})$ rendered typical PLLA crystals with a lozenge morphology and an angle of $120^{\circ}$ between between their $\{110\}$ faces (Figure 6a). These crystals had a multiterrace appearance, AFM images indicating the existence of individual lamellae. The thickness of such lamellae $(\sim 3.5 \mathrm{~nm})$, which was determined from the corresponding height profiles, is lower than the length of the molecular chain and, therefore, folding took place despite the low molecular weight. Besides, polarizing optical micrographs proved the positive birefringence of the crystals, which agrees in with the results discussed in the previous section (Figure 5). Thus, typical PLLA crystals are formed despite the presence of $b \mathrm{Phe}_{n}$ and the moderate size of the PLLA block.

Spherulitic morphologies were preferably obtained when the viscosity of the solution increased with the size of the PLLA block. The best developed structures were obtained by evaporation at room temperature of tetrahydrofurane solutions at the same polymer 
concentration $(10 \mathrm{mg} / \mathrm{mL})$. Lozenge single crystals characterized by a nucleation center (red arrows in Figure 6b) can be observed, even though the predominant structure corresponds to spherulites with a ringed texture and a negative birefringence sign (Figure 6c). The presence of fibrils was consistent with an edge-on lamellar structure (light blue arrows in Figures 6c-f) and the negative birefringence. SEM micrographs (Figures 6d-e) displays a ringed appearance due to the crystallization on progressive circular fronts originated by the evaporation of the solvent. The development of radial aggregates that become progressively split is clearly illustrated in Figure 6e, whereas the regular disposition of these aggregates constituted by edge-on crystals can be envisaged in the AFM image (Figure 6f).

The increase on the crystallization rate induced by the addition of a precipitation agent gave rise to worse morphologies, as for example spheres derived from a typical phase separation in a bad solvent (Figure S2a), flower-like aggregates of lozenge crystals (Figure S2b) and fibrillar aggregates (Figure S2c). Phase separation was characteristic of drastic conditions provided by low temperature $\left(4^{\circ} \mathrm{C}\right)$, high precipitant ratio (THF: $\mathrm{H}_{2} \mathrm{O}$ 1:9) and low PLLA content (e.g. Phe 2 - $b$-PLLA 22 ), whereas higher temperatures $\left(25^{\circ} \mathrm{C}\right)$, low precipitant content (THF: $\mathrm{H}_{2} \mathrm{O}$ 4:1) and high PLLA content (e.g. $\mathrm{Phe}_{2}-b$-PLLA 45$)$ favoured the development of single crystals. Crystallization was also affected by the ionic content of the medium, causing the development of distinctive fibrillar aggregates (Figure S2c).

Formation of dendritic structures was also a general characteristic of the studied copolymers as shown in the optical micrographs (Figure 7a) and the AFM images (Figures 7a-b) recorded for $\mathrm{Ph}_{3} \mathrm{PLLa}_{20}$. Although fibrous dendritic morphologies have been reported for low molecular weight PLLA, ${ }^{51}$ dendritic morphologies formed 
through the self-assembly of $\mathrm{Phe}_{3^{-}}$and $\mathrm{Phe}_{4}$-oligomers ${ }^{32,33}$ were the most similar to those displayed in Figures 7a-c.

Finally, morphologies that are not usual in PLLA but have been reported for selfassembled Phe-oligomers ${ }^{31-34}$ were obtained for copolymers with short PLLA blocks by evaporation of dichloromethane solutions and subsequent thermal treatment. Specifically, straight microfibers with a diameter in the $2.0-3.5 \mu \mathrm{m}$ range (Figure $7 \mathrm{~d}$ ) were observed together with stacked braid-like microstructures (Figure 7e). AFM images suggest that microfibers are apparently constituted by several assembled (Figure 7d). The braid-like microstructures observed in the boundaries of the glass coverslips are very similar to those detected for short Phe-oligomers. The formation of this complex microstructure was attributed to the presence of multiple interfaces at such location. $^{31-34}$

\section{Conclusions}

Phe macroinitiators for the ROP of lactide have been used to produce diblock copolymers. The size of the $b \mathrm{Phe}_{n}$ and the PLLA blocks has been successfully controlled through the monomer / initiator ratio used in the two polymerization steps: the ROP of Phe-NCA using butylamine as initiator and the ROP of lactide using the macroinitiator. The main limitation of such methodology is the scarce solubility of the macroinitiator in the lactide medium, which results in an enlargement of the reaction time. Hybrids were synthesized with a lactide content higher then 63 wt- $\%$, being crystalline with a predominant phase corresponding to the $\alpha$-form of PLLA. However, X-ray diffraction peaks associated with the peptide structure have also been detected. DSC traces showed the crystallization and melting peaks of the PLLA phase only, indicating that the peptide assemblies decomposed during heatig before reaching their 
fusion. Copolymers degrade thermally following two decomposition steps, which have been associated to each constitutive block. The onset of degradation was relatively low, and consequently a strict control on the reaction temperature was imprecindible to avoid the occurrence of degradation during synthesis.

Crystallization from the melt, which is characterized by a high nucleation that has been avoided by inducing a phase separation through an annealing process, provides spherulites with a distinctive lamellar disposition (i.e. flat-on or edge-on) and birefringence (i.e. negative or positive) as a function of the Phe-block length. Crystallization from diluted solutions opens a wide variety of possibilities (control of temperature, concentration, solvent and precipitant agent), leading to a great diversity of crystalline morphologies. Although the most usual ones correspond to single crystals and spherulites typically obtained from PLLA, morphologies previously reported in self-assembling studies of Phe-homopeptides have also been visualized.

\section{Acknowledgments}

The authors thank MINECO and FEDER (MAT2015-69367- R, MAT2015-69547-R, and CTQ2013-40855-R), the Generalitat de Catalunya (2014SGR188) and Gobierno de Aragoń-FEDER (research group E40). Support for the research of C.A. was received through the prize "ICREA Academia" for excellence in research funded by the Generalitat de Catalunya. 


\section{References}

1. M. Morell and J. Puiggalí, Polymers, 2013, 5, 188-224.

2. H. Schlaad and M. Antonietti, Eur. Phys. J. E, 2003, 10, 17-23.

3. H. A. Klok and L. Ayres, Peptide Hybrid Polymers, ed. H. A. Klok and H. Schlaad, Springer, Berlin, Germany, 2006.

4. H. G. Börner, Prog. Polym. Sci., 2009, 34, 811-851.

5. J. F. Lutz and H. G. Börner, Prog. Polym. Sci., 2008, 33, 1-39.

6. B. D. Ulery, L. S. Nair and C. T. Laurencin, J. Polym. Sci. B. Polym. Phys., 2011, 49, $832-864$.

7. L. S. Nair and C. T. Laurencin, Adv. Biochem. Eng. Biotechnol., 2006, 102, 47-90.

8. S. Agarwal, J. H. Wendorff and A. Greiner, Polymer, 2008, 49, 5603-5621.

9. W. Lu, J. Sun and X. Jiang, J. Mater. Chem. B, 2014, 2, 2369-2380.

10. D. L. Leslie-Pelecky and V. D. Labhasetwar, Biomedical applications of nanotechnology. (John Wiley, 2007). at <http://cataleg.upc.edu/record=b1313825 S1*cat>

11. H. Tian, Z. Tang, X. Zhuang, X. Chen and X. Jing, Prog. Polym. Sci., 2012, 37, $237-280$.

12. M. A. Gauthier and H. A. Klok, Chem. Commun., 2008, 23, 2591-2611.

13. B. Le Droumaguet and K. Velonia, Macromol. Rapid. Commun., 2008, 29, 10731089.

14. H. A. Klok, Macromolecules, 2009, 42, 7990-8000.

15. H. R. Marsden and A. Kros, Macromol. Biosci., 2009, 9, 939-951.

16. H. R. Kricheldorf and K. Hauser, Biomacromolecules, 2001, 2, 1110-1115.

17. J. Liu, C. Zhang and L. Liu, J. Appl. Polym. Sci., 2008, 107, 3275-3279. 
18. S. Caillol, S. Lecommandoux, A. F. Mingotaud, M. Schappacher, A. Soum, N. Bryson and R. Meyrueix, Macromolecules, 2003, 36, 1118-1124.

18. J. P. Jain, W. Yenet Ayen, A. J. Domb and N. Kumar, Biodegradable polymers in drug delivery, in Biodegradable polymers in clinical use and clinical develompent, eds. A. J. Domb and N. Kumar and A. Ezra, John Wiley \& Sons, Inc., New Jersey, 2011, pp: $3-58$

19. B. Lotz, Adv. Polym. Sci. (2017), in press.

20. W. Hoogsten, A. R. Postema, A. J. Pennings, G. Ten Brinke, P. Zugenmaier, Macromolecules, 1990, 23, 634-642.

21. K. Wasanasuk and K. Tashiro, Macromolecules, 2011, 44, 9650-9660.

22. K. Wasanasuk and K. Tashiro, Polymer, 2011, 52, 6097-6109.

23. J. Puiggalí, Y. Ikada, H. Tsuji, L. Cartier, T. Okihara, B. Lotz, Polymer, 2000, 41 8921-8930.

24. L. Cartier, T. Okihara, Y. Ikada, H. Tsuji, J. Puiggalí and B. Lotz, Polymer, 2000, 41, 8909-8919.

25. Y. W. Cho, J. Lee, S. C. Lee, K. M. Huh and K. Park, J. Control. Release, 2004, 97, 249-257.

26. H. Cao, J. Yao and Z. Shao, Polym. Int., 2012, 61, 774-779.

27. M. S. Kim, K. Dayananda, E. K. Choi, H. J. Park, J. S. Kim and D. S. Lee, Polymer, 2009,. 50, 2252-2257.

28. M. Reches and E. Gazit, Science, 2003, 300, 625-627.

29. Y. Song, S. R. Challa, C. J. Medforth, Y. Qiu, R. K. Watt, D. Pena, J. E. Miller, F. V. Swol and J. A. Shelnutt, Chem. Commun., 2004, 7, 1044-1045.

30. V. V. Korolkov, S. Allen, C. J. Roberts and S. J. B. Tendler, Faraday Discuss., 2013, 166, 331-348. 
31. E. Mayans, G. Ballano, J. Casanovas, A. Díaz, M.-M. Perez-Madrigal,' F. Estrany, J. Puiggalí, C. Cativiela and C. Aleman, Chem. Eur. J., 2015, 21, 16895- 16905.

32. E. Mayans, J. Casanovas, A. M. Gil, A. I. Jiménez, C. Cativiela, J. Puiggalí and C. Alemán, Langmuir, 2017, 33, 4036-4048.

33. E. Mayans, G. Ballano, J. Casanovas, L. J. del Valle, M. M. Perez-Madrigal, F. Estrany, A. I. Jimenez, J. Puiggalí, C. Cativiela and C. Aleman, Soft Matter, 2016, 12, $5475-5488$.

34. E. Mayans, G. Fabregat, R. Juarez, C. Cativiela, J. Puiggalí and C. Alemán, Chem. Select, 2017, 23, 1133-1139.

35. A. Gemma, E. Mayans, G. Ballano, J. Torras, A. Díaz, A. I. Jiménez, J. Puiggalí, C. Cativiela and C. Alemán, Phys. Chem. Chem. Phys., 2017, 19, 27038-27051.

36. E. Mayans, G. Ballano, J. Sendros, M. Font-Bardia, J. L. Campos, J. Puiggalí, C. Cativiela and C. Alemán, Chem.Phys.Chem., 2017, 18, 1888-1896.

37. X. Yan, P. Zhu and J. Li, Chem. Soc. Rev., 2010, 39, 1877-1890.

38. S. Fleming and R. V. Ulijn, Chem. Soc. Rev., 2014, 43, 8150-8177.

39. Peptide Materials: From Nanostructures to applications, C. Alemán, A. Bianco and M. Venanzi (Eds), Wiley, 2013

40. M. Planellas and J. Puiggalí, Int. J. Mol. Sci., 2014, 15, 13247-13266.

41. H. Leuchs, Berichte der Dtsch. Chem. Gesellschaft, 1906, 39, 857-861.

42. F. Fuchs, Berichte der Dtsch. Chem. Gesellschaft, 1922, 55, 2943-2943.

43. A. C. Farthing and R. J. W. Reynolds, Nature, 1950, 165, 647-647.

44. A. C. Farthing, A. C. J. Chem. Soc., 1950, 3213-3217.

45. W. H. Daly and D. Poché, Tetrahedron Lett., 1988, 29, 5859-5862.

46. H. R. Kricheldorf, C. V. Lossow and G. Schwarz, Macromol. Chem. Phys., 2005, 206, 282-290. 
47. S. K. Murase, N. Haspel, L. J. del Valle, R. Nussinov, J. Puiggalí and C. Alemán, RSC Adv., 2014, 4, 23231-23241.

48. B. Lotz and A. Brack, The use of polypeptides as models in fibrous protein structure investigations. In Applied Fibre Science, F. Happey, Ed.; Academic Press: London, UK, 1979, Volume 3, pp. 371-410.

49. H. Tsuji, Polymer, 1995, 36, 2709-2716.

50. H. Tsuji, Y. Tezuka, S. K. Saha, M. Suzuki and S. Itsuno, Polymer, 2005, 46, 49174927.

51. E. W. Woo, H. Ni'mah and Y.-H. Wang, Ind. Eng. Che. Res., 2014, 53, 9772-9780. 


\section{FIGURE CAPTIONS}

Figure 1. Synthesis schemes for the preparation of PPhe homopolymer (a) and the PPhe- $b$-PLA diblock copolymer (b).

Figure 2. (a) MALDI-TOF-MS spectrum of $b \mathrm{Phe}_{15}$. The inset shows a magnifiaction of a small area and indicates the presence of differently charged copolymers. The highest signal corresponded to a molecular weight of $3528 \mathrm{~g} / \mathrm{mol}$. (b) ${ }^{1} \mathrm{H}$ and ${ }^{13} \mathrm{C}$ NMR spectra of the representative $\mathrm{Phe}_{25}-b$-PLLA 100 sample (top and bottom, respectively).

Figure 3. (a) FTIR spectra of PLLA, $b \mathrm{Phe}_{25}$ and $\mathrm{Phe}_{25}$ - $b$-PLLA 100 . (b) UV-vis spectra of a commercial PLLA (i), synthesized $b \mathrm{Phe}_{8}$ (ii), $\mathrm{Phe}_{8}-b$-PLLA 55 (iii), $\mathrm{Phe}_{15}-b-\mathrm{PLLA}_{50}$ (iv) and $\mathrm{Phe}_{25}-b-\mathrm{PLLA}_{100}(v)$.

Figure 4. (a) TGA and DTGA curves for the $\mathrm{Phe}_{8}-b-\mathrm{PLLA}_{55}$, commercial PLLA and $b \mathrm{Phe}_{8}$. (b) DSC traces for the $\mathrm{Phe}_{8}-b$-PLLA 55 copolymer showing the first heating scan of the solution purified sample $(i)$, the cooling run from the melt state after keeping the sample for 5 minutes above fusion (ii), the second heating scan of the melt crystallized sample (iii) and, finally, the third heating run of a sample previously quenched from the melt state $(i v)$.

Figure 5. Optical micrographs of $\mathrm{Phe}_{25}-b$-PLLA 100 spherulites obtained in isothermal crystallizations from the melt state at $118{ }^{\circ} \mathrm{C}(\mathrm{a}-\mathrm{c}), 120^{\circ} \mathrm{C}(\mathrm{d}, \mathrm{e})$ and $115^{\circ} \mathrm{C}$ (f). Ellipsoids points out the formation of branched crystals from the main radial lamella. Polarized optical micrographs of $\mathrm{Phe}_{2}-b-\mathrm{PLLA}_{45}(\mathrm{~g}, \mathrm{~h}), \mathrm{Phe}_{3}-b-\mathrm{PLLA}_{44}$ (i), $\mathrm{Phe}_{4}-b$ $\operatorname{PLLA}_{60}(\mathrm{j})$ and $\mathrm{Phe}_{5}-b-\mathrm{PLLA}_{50}(\mathrm{k}, \mathrm{l})$ spherulites crystallized at $115^{\circ} \mathrm{C}(\mathrm{g}, \mathrm{i}-\mathrm{k}), 125^{\circ} \mathrm{C}(\mathrm{h})$ and $135^{\circ} \mathrm{C}(\mathrm{l})$.

Figure 6. (a) Lozenge crystals of $\mathrm{Phe}_{2}-b-\mathrm{PLLA}_{22}$ obtained by evaporation of dichloromethane solutions. Polarizing optical micrographs (left) show the change of 
birefringence according the the orientation of the crystal, while AFM micrograph and the heigh profile reflect a multi-layered distribution and regular widthness. Typical $\mathrm{Phe}_{2}-b$-PLLA 45 morphologies obtained by slow evaporation of dichloromethane solutions: (b,c) Optical and (d,e) SEM micrographs, and (f) AFM image $\left(40 \times 40 \mu \mathrm{m}^{2}\right)$ show the development of lozenge crystals (b) and spherulitic aggregates (c-f).

Figure 7. Optical micrograph (a) and AFM images (b,c) of dendritic morphologies obtained for $\mathrm{Phe}_{3}-b-\mathrm{PLLA}_{20}$ in THF: $\mathrm{H}_{2} \mathrm{O}$ 1:9 with $\mathrm{Na}_{2} \mathrm{CO}_{3} 0.5 \mathrm{M}(\mathrm{a}, \mathrm{b})$ and in $\mathrm{CH}_{2} \mathrm{Cl}_{2}: \mathrm{CH}_{3} \mathrm{OH}$ 13:1 (c). The copolymer concentration in the solvent mixtures was always $10 \mathrm{mg} / \mathrm{mL}$. (d) Optical micrograph showing straight microfibers of $\mathrm{Phe}_{2}-b$ PLLA $_{20}$ obtained from evaporation at $25^{\circ} \mathrm{C}$ of dilute polymer solutions $(10 \mathrm{mg} / \mathrm{mL})$ in $\mathrm{CH}_{2} \mathrm{Cl}_{2}$ and subsequent treatment at $120^{\circ} \mathrm{C}$ for $12 \mathrm{~h}$. Images at the bottom correspond to a low magnification with a complete spheric aggregate and an AFM image of a microfiber $\left(10.0 \times 6.5 \mu \mathrm{m}^{2}\right)$. (e) Optical micrograph of complex aggregates obtained for $\mathrm{Phe}_{2}-b$-PLLA 20 under the conditions indicated in (d). Inset shows a SEM micrograph of shuch type of aggregate. 
Table 1. Reaction conditions for ROP of L-Phe-NCA and final degrees of polymerization.

\begin{tabular}{|c|c|c|c|c|c|c|c|}
\hline Name & M/I ratio ${ }^{a}$ & $\begin{array}{c}\mathbf{M n}^{\mathbf{b}} \\
(\mathrm{g} / \mathrm{mol})\end{array}$ & $\begin{array}{c}\text { Temperature } \\
\left({ }^{\circ} \mathrm{C}\right)\end{array}$ & $\begin{array}{c}\text { Time } \\
\text { (h) }\end{array}$ & $\begin{array}{c}\text { Conversion }^{\mathbf{c}} \\
(\%)\end{array}$ & DPPhe $^{d}$ & $\begin{array}{c}\boldsymbol{M n}^{\mathbf{e}} \\
(\mathrm{g} / \mathrm{mol})\end{array}$ \\
\hline$b \mathrm{PPhe}_{4}$ & 20 & 3047 & 40 & 24 & 87 & 3.3 & $592^{f}$ \\
\hline$b \mathrm{PPhe}_{8}$ & 10 & 1577 & 60 & 48 & 80 & 7.8 & 1254 \\
\hline$b \mathrm{PPhe}_{15}$ & 20 & 3047 & 60 & 48 & 94 & 14.8 & 2283 \\
\hline$b \mathrm{PPhe}_{25}$ & 40 & 5987 & 60 & 48 & 96 & 25 & 3782 \\
\hline
\end{tabular}

${ }^{\mathrm{a}} \mathrm{Phe}-\mathrm{NCA} /$ benzylamine ratio introduced in the reaction flask.

${ }^{\mathrm{b}}$ Theoretical value calculated from the monomer / initiator ratio (M / I) ratio introduced in the reaction flask, the repeat unit molecular weight and the molecular weight of the terminal units: $\mathrm{M} / \mathrm{I} \times 147+107$.

${ }^{\mathrm{c}}$ Experimental value calculated from ${ }^{1} \mathrm{H}$ NMR spectra of as-synthesized samples using $\mathrm{CH}-$ and $-\mathrm{NH}-$ signals of Phe and Phe-NCA, respectively.

${ }^{\mathrm{d}}$ Experimental degree of polymerization of Phe-blocks calculated from ${ }^{1} \mathrm{H}$ NMR spectra of purified samples using $-\mathrm{CH}-$ and $-\mathrm{CH}_{2}-$ signal of Phe and bezylamine, respectively.

${ }^{\mathrm{e}}$ Experimental value determined using the experimental value of $\mathrm{DP}_{\mathrm{Phe}}$ and adding the molecular weight of the terminal groups.

${ }^{\mathrm{f}}$ The polymer was obtained under a lower reaction temperature (i.e. $40{ }^{\circ} \mathrm{C}$ instead of 60 ${ }^{\circ} \mathrm{C}$ ), which required a higher $\mathrm{M} / \mathrm{I}$ ratio and had a drastic effect in the resulting peptide size. 
Table 2. Molecular weight and block lengths of synthesized hybrid samples.

\begin{tabular}{|c|c|c|c|c|c|c|c|c|}
\hline Name & $\begin{array}{l}\text { Time } \\
\text { (days) }\end{array}$ & $\mathbf{M} / \mathbf{I}^{\mathbf{a}}$ & $\begin{array}{c}\boldsymbol{M}_{\boldsymbol{n}}^{\mathbf{b}} \\
(\mathrm{g} / \mathrm{mol})\end{array}$ & $\begin{array}{c}\boldsymbol{M}_{\boldsymbol{w}}^{\mathbf{b}} \\
(\mathrm{g} / \mathrm{mol})\end{array}$ & $\mathbf{P D I}^{\mathrm{b}}$ & $\begin{array}{c}\text { Conversion }^{\mathbf{c}} \\
(\%)\end{array}$ & $D_{P L L A}{ }^{d}$ & $\begin{array}{r}\text { Peptide }^{\mathrm{d}} \\
(\mathrm{wt}-\%)\end{array}$ \\
\hline Phe $_{2}-b$-PLLA 45 & 5 & 25 & 3500 & 5.300 & 1.5 & 87 & 45 & 8 \\
\hline $\mathrm{Phe}_{3}-b$-PLLA $_{15}$ & 5 & 10 & 1540 & 2200 & 1.4 & 85 & 15 & 29 \\
\hline $\mathrm{Phe}_{4}-b-$ PLLA $_{22}$ & 6 & 15 & 2190 & 3500 & 1.6 & 83 & 22 & 26 \\
\hline $\mathrm{Phe}_{8}-b-$ PLLA $_{55}$ & 6 & 30 & 5100 & 7000 & 1.4 & 88 & 55 & 22 \\
\hline $\mathrm{Phe}_{15}-b-\mathrm{PLLA}_{50}$ & 7 & 30 & 5800 & 14400 & 2.5 & 85 & 50 & 37 \\
\hline $\mathrm{Phe}_{25}-b$-PLLA 100 & 7 & 50 & 11000 & 26100 & 2.4 & 83 & 100 & 33 \\
\hline
\end{tabular}

${ }^{\mathrm{a}} \mathrm{L}$-lactide (monomer) and peptide (initiator) ratio introduced in the reaction flask.

${ }^{\mathrm{b}}$ Values determined by GPC.

${ }^{c}$ Calculated from ${ }^{1} \mathrm{H}$ NMR of as-synthesized samples using the $-\mathrm{CH}-$ and $-\mathrm{CH}_{3}$ signals of L-lactide and PLLA.

${ }^{\mathrm{d}}$ Calculated from ${ }^{1} \mathrm{H}$ NMR of purified samples using the $-\mathrm{CH}-$ signals of inner and terminal PLLA units.

${ }^{\mathrm{e}}$ Number of lactic acid units calculated from ${ }^{1} \mathrm{H}$ NMR of purified samples using $-\mathrm{CH}-$ signals of PLLA and $b \mathrm{Phe}_{n}$ units. 
Table 3. Calorimetric data of representative hybrid copolymers. ${ }^{a}$

\begin{tabular}{|c|c|c|c|c|c|}
\hline Sample & $\begin{array}{c}\mathbf{T}_{\mathbf{g}} \\
\left({ }^{\circ} \mathrm{C}\right)\end{array}$ & $\begin{array}{c}\mathbf{T}_{\mathbf{c}} \\
\left({ }^{\circ} \mathrm{C}\right)\end{array}$ & $\begin{array}{l}\Delta \mathbf{H}_{\mathbf{c}} \\
(\mathrm{J} / \mathrm{g})\end{array}$ & $\begin{array}{c}\mathbf{T}_{\mathbf{m}} \\
\left({ }^{\circ} \mathrm{C}\right)\end{array}$ & $\begin{array}{r}\Delta \mathbf{H}_{\mathbf{m}} \\
(\mathrm{J} / \mathrm{g})\end{array}$ \\
\hline $\mathrm{Phe}_{2}-b-\mathrm{PLLA}_{45}$ & 51 & 97 & 23.0 & 141 & 35 \\
\hline $\mathrm{Phe}_{8}-b-\mathrm{PLLA}_{55}$ & 55 & 106 & 22.5 & 139 & 23 \\
\hline $\mathrm{Phe}_{15}-b$ PLLA $_{50}$ & 54 & 97 & 19.2 & 128 & 6.7 \\
\hline $\mathrm{Phe}_{25}-b-\mathrm{PLLA}_{100}$ & 54 & 106 & 20 & 132 & 21.3 \\
\hline
\end{tabular}

${ }^{\mathrm{a}}$ Obtained from a heating run after quenching. 
(a)

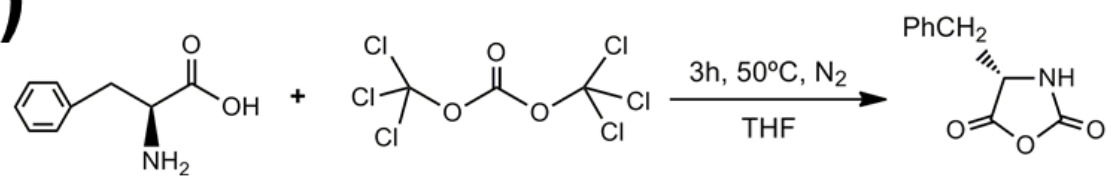

Phe

Triphosgene

Phe-NCA

$\mathrm{PhCH}_{2}$

Phe-NCA

(b)

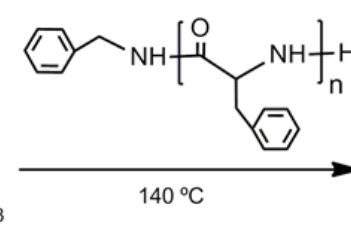

L-lactide

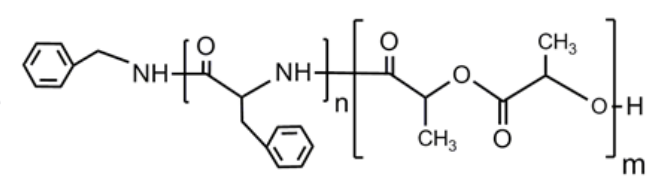

Phe $_{n-} b$-PLLA

Figure 1 


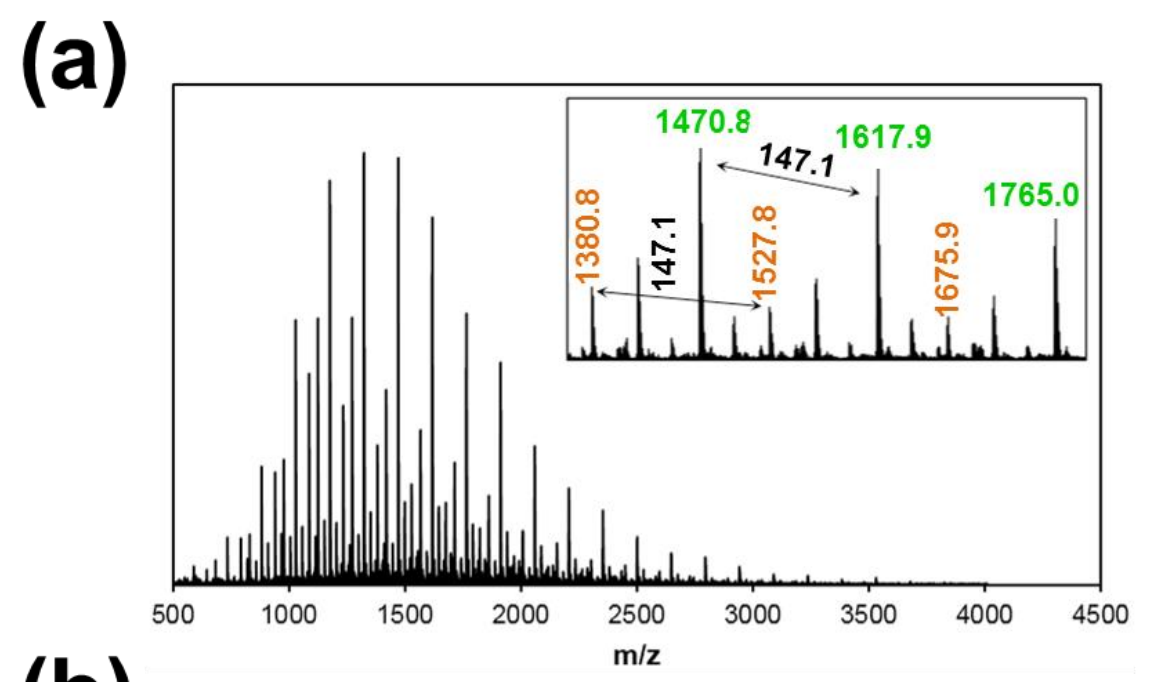

(b)
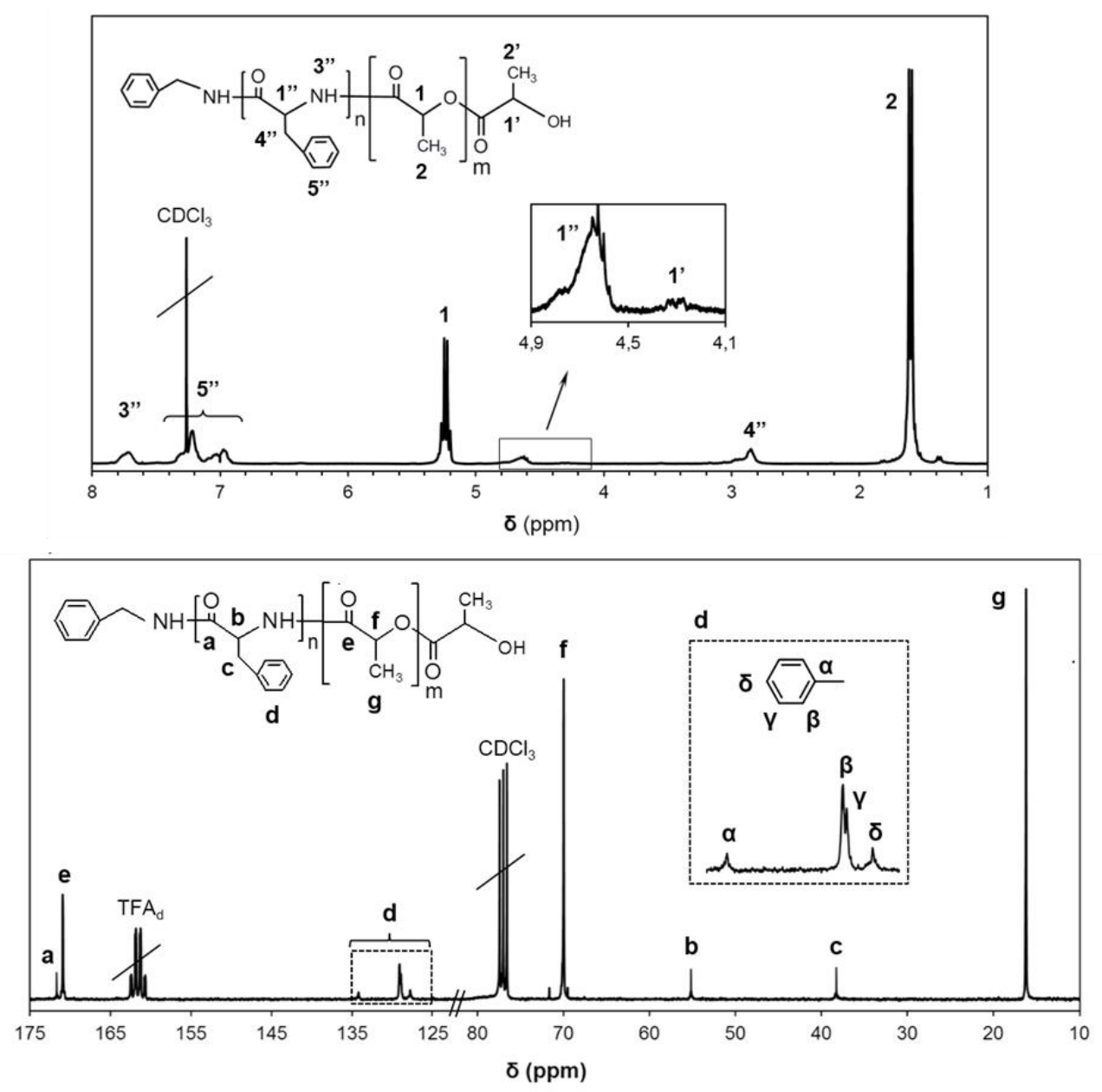

Figure 2 
(a)

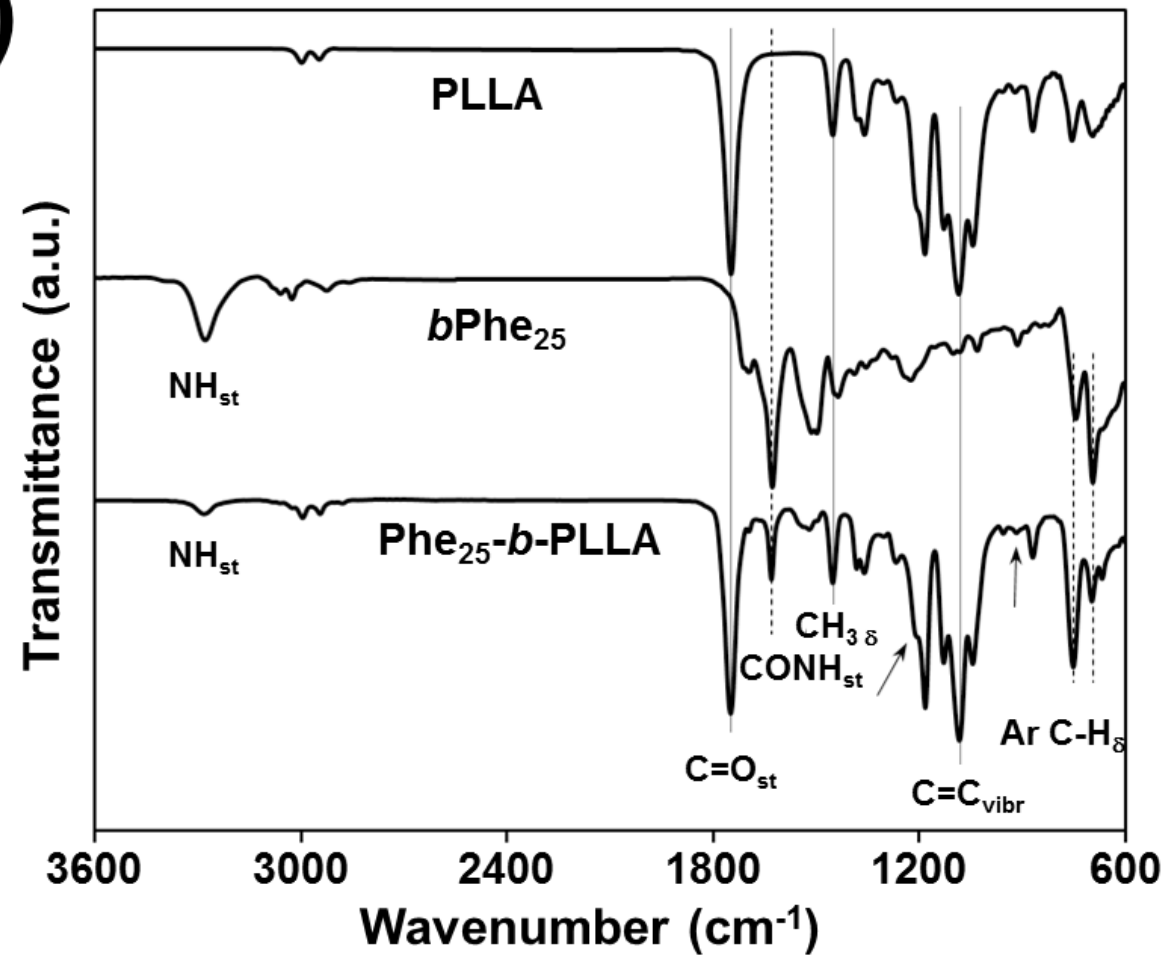

(b)

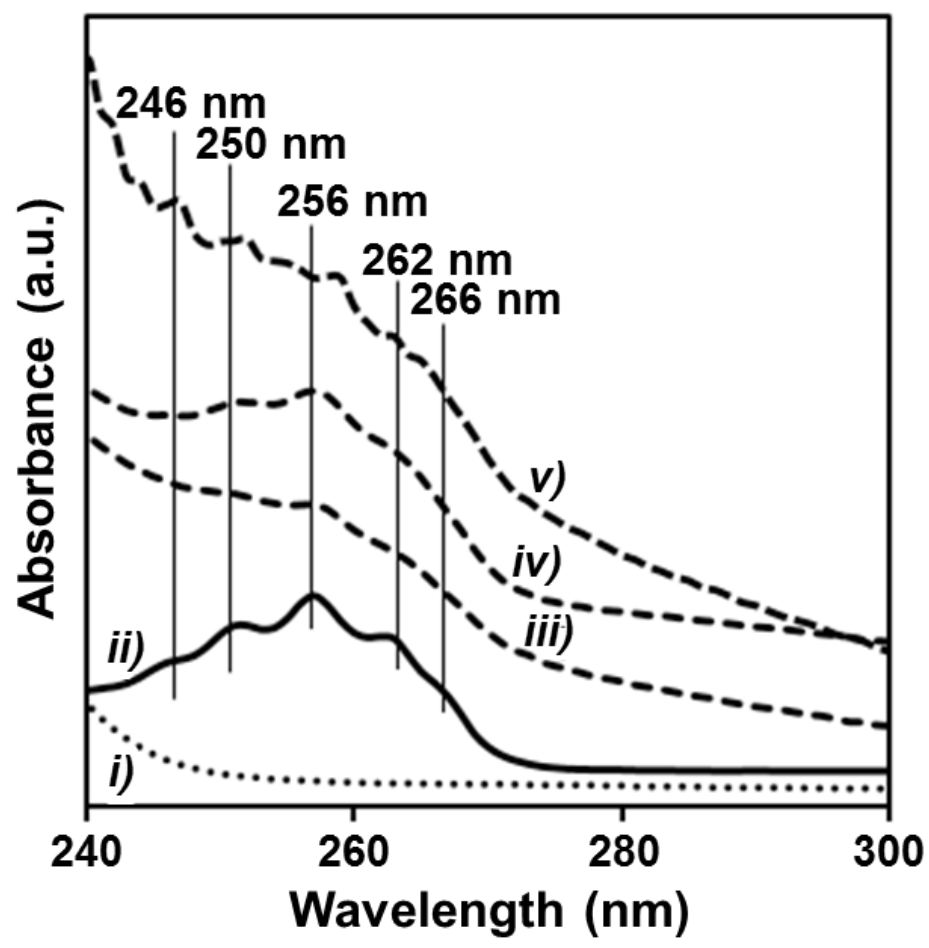

Figure 3 
(a)

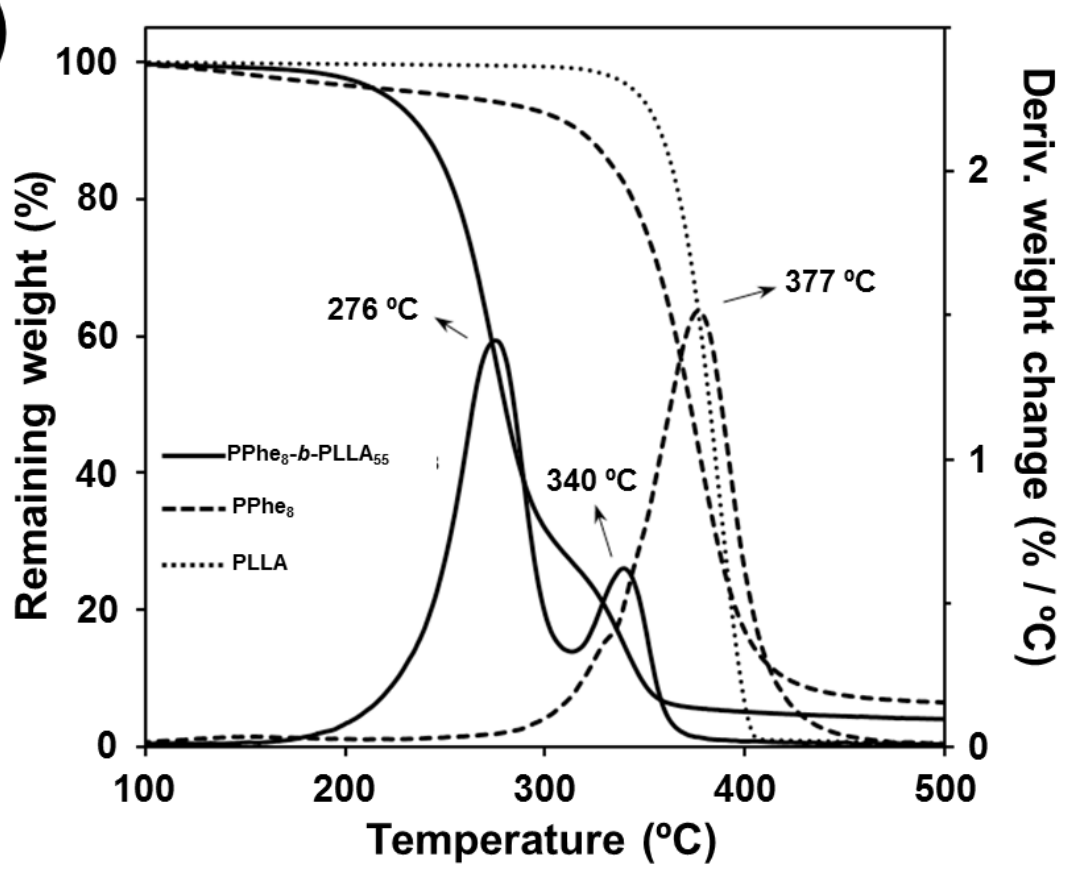

(b)

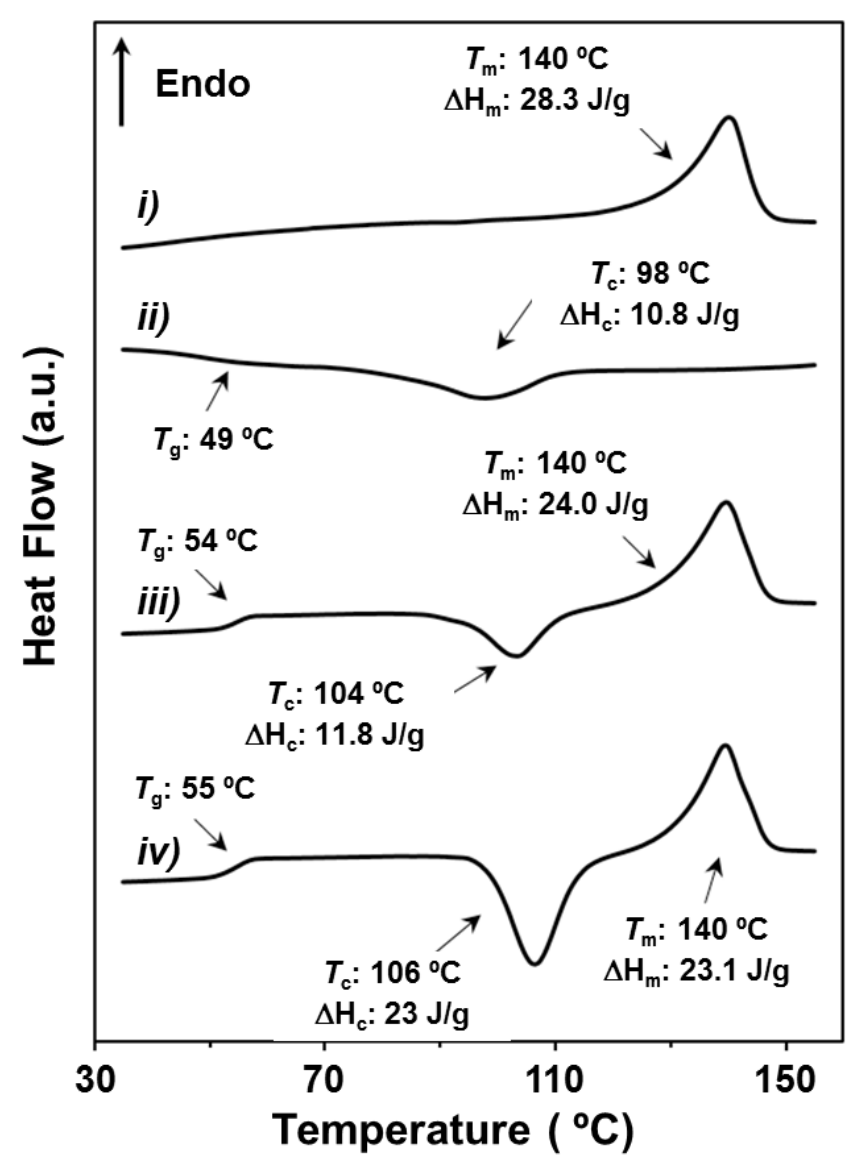

Figure 4 

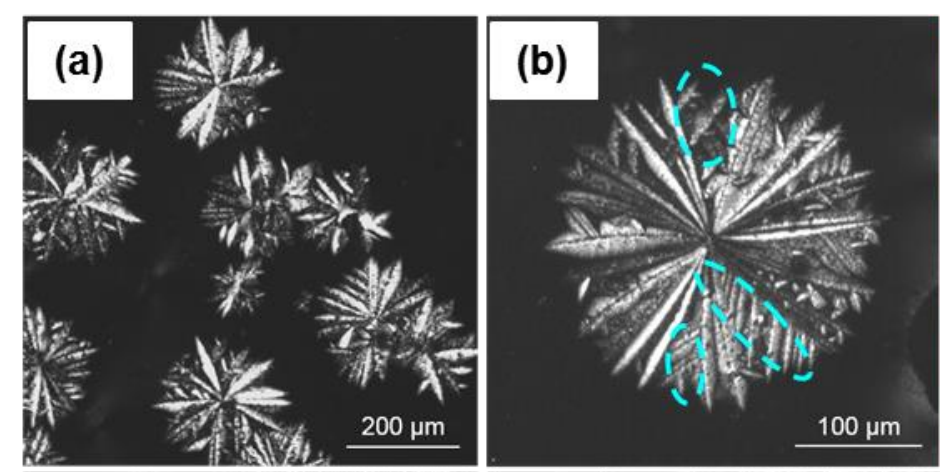

(c)
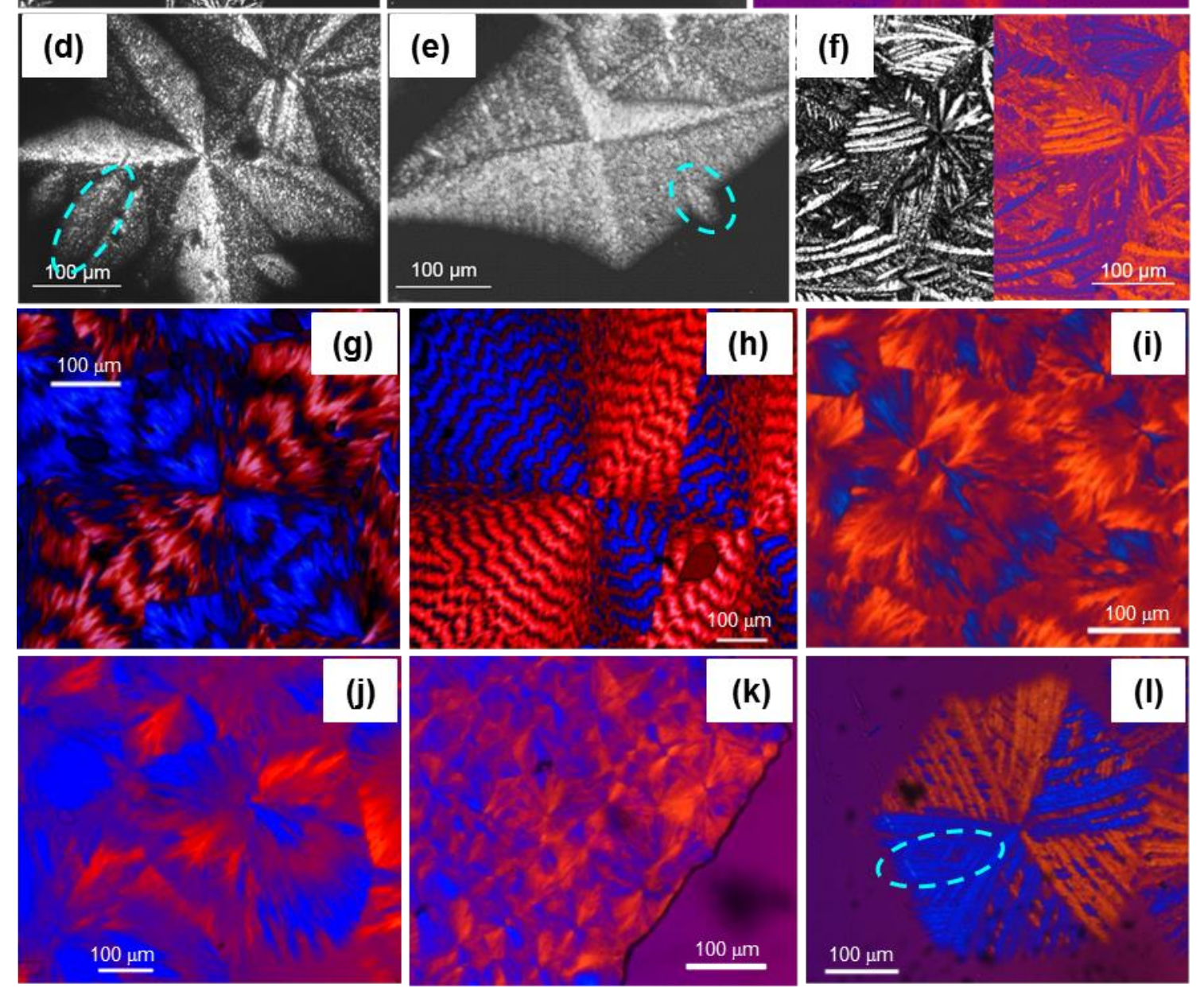

Figure 5 


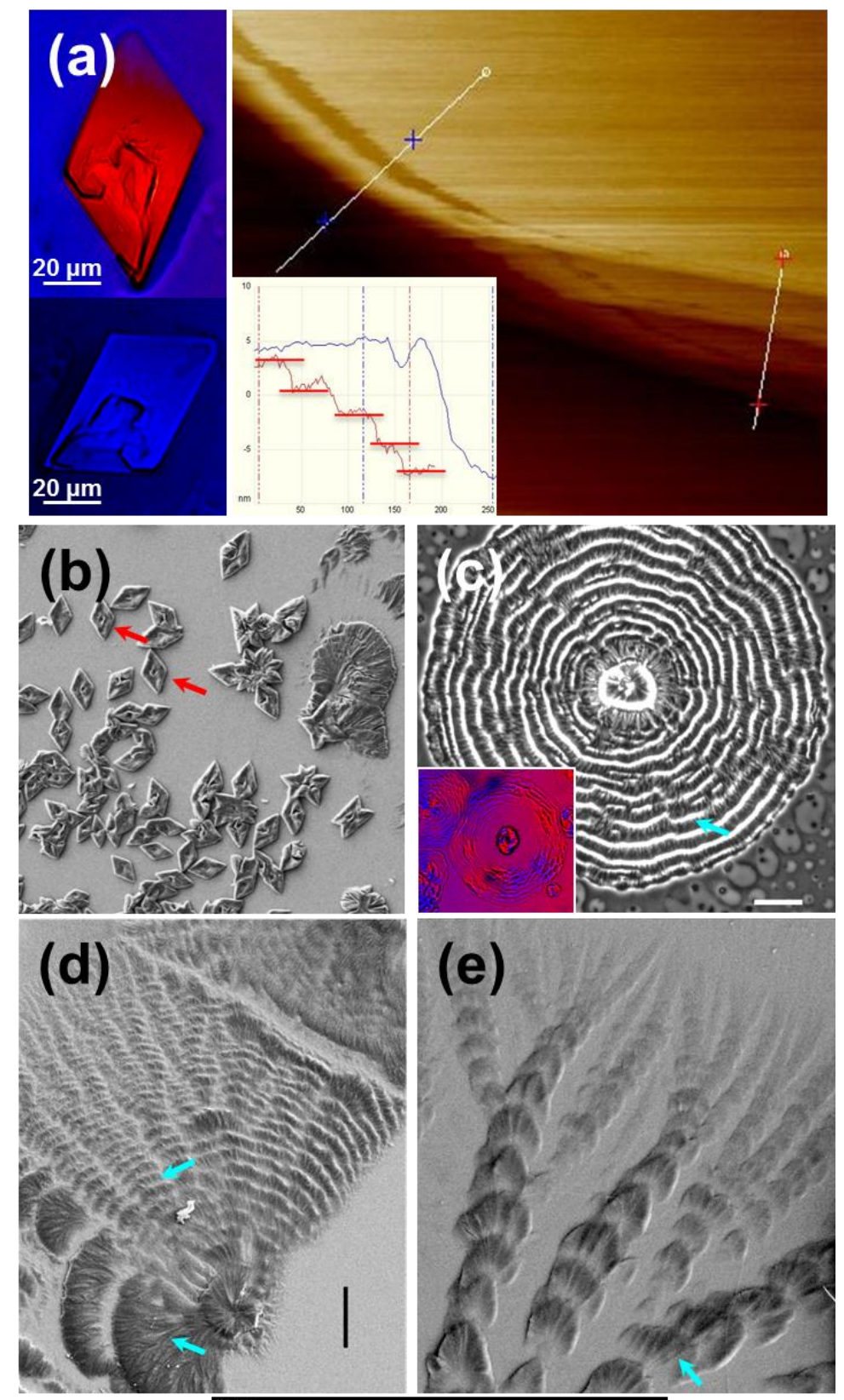

(f)

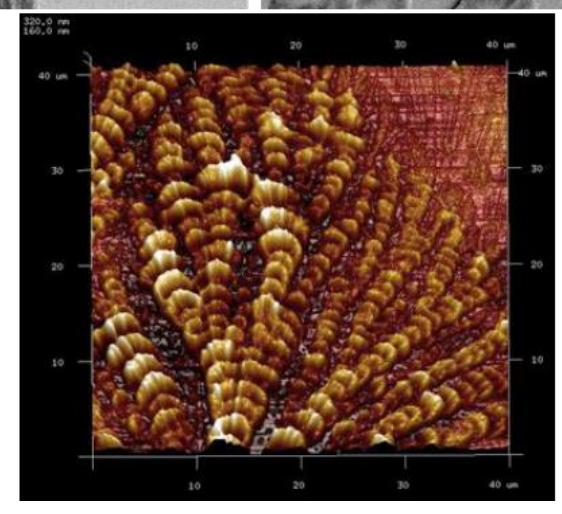

Figure 6: HAY OTRA DE AFM Q SE PUEDA PONER?? 

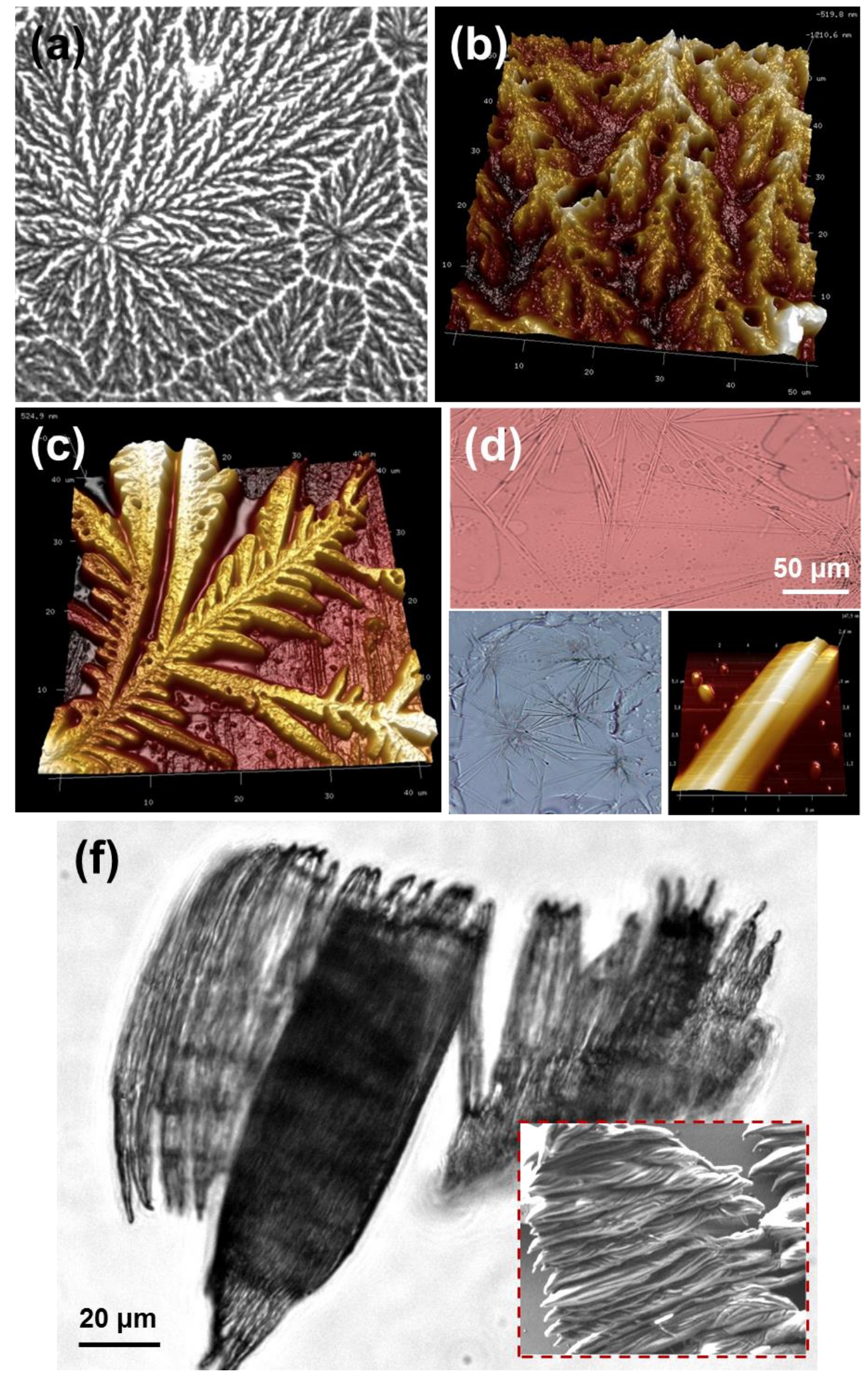

Figure 7 